\title{
Measuring Leaf Water Potential ${ }^{1}$
}

\section{Christian Bartell, Haimanote K. Bayabil, Bruce Schaffer, Fitsum Tilahun, and Fikadu Getachew²}

\section{Introduction}

Understanding plants' responses to water stress is essential to achieving optimal plant growth and yield. Leaf water potential can be an indicator of plant water stress as a function of soil water availability. Leaf water potential measurements have been used to develop plant-based irrigation scheduling methods (Fulton et al. 2001). This article summarizes the basic concepts of leaf water potential measurements and two available methods for measuring leaf water potential under field and laboratory conditions. The information included in this document could be of interest to students, researchers, Extension agents, and growers.

\section{What is leaf water potential?}

Plants have a vascular system that contains a water column under constant tension (Waring and Cleary 1967). Water moves from the roots to the leaves through a series of interconnected "pipes" known as xylem. As water evaporates from the leaves through small openings on the leaf surface called stomata, a suction force is produced by the vascular system as the plant continually pulls water from the roots through the xylem, creating tension. This process is affected by environmental factors such as air temperature, humidity, wind, and soil water availability. As soils become dry, the tension within the plant increases because it becomes more difficult for the roots to extract water from the soil. Under such conditions, water in leaves will be tightly held; the amount of tension it takes for the water to move out of the leaves corresponds to soil moisture availability. This publication discusses the steps of leaf sample preparation and two methods for measuring leaf water potential.

\section{Measuring Leaf Water Potential}

Measuring water potential can provide information on the soil moisture content for a particular plant by determining the amount of effort, or pressure, the plant is exhibiting while pulling water from the soil. Plants under higher turgor pressure (osmotic flow of water) indicate low soil moisture content, while low pressure indicates higher soil moisture content. This information can help in identification of the most critical periods to irrigate based on the plants' needs. The standard device used to measure leaf water potential is the Scholander pressure chamber, also referred to as a "pressure bomb" shown in Figure 1 (Cochard et al. 2001; Scholander et al. 1965). A pump-up chamber (Figure 2) is also commercially available (@ 2021 PMS Instrument Company, Oregon, US) as a simpler and cheaper alternative to a pressure "bomb." The pump-up chamber is a manually pressurized chamber that does not require compressed gas, making it ideal for rapid, multiple field measurements.

1. This document is AE563, one of a series of the Department of Agricultural and Biological Engineering, UF/IFAS Extension. Original publication date October 2021. Visit the EDIS website at https://edis.ifas.ufl.edu for the currently supported version of this publication.

2. Christian Bartell, engineer I, Department of Agricultural and Biological Engineering; Haimanote K. Bayabil, assistant professor, Department of Agricultural and Biological Engineering; Bruce Schaffer, professor, ecophysiology of subtropical and tropical horticultural crops, Horticultural Sciences Department; Fitsum Tilahun, Ph.D. student, Department of Agricultural and Biological Engineering; and Fikadu Getachew, Ph.D. student, crop modeling, Department of Agricultural and Biological Engineering; UF/IFAS Tropical Research and Education Center, Homestead, FL 33031.

The Institute of Food and Agricultural Sciences (IFAS) is an Equal Opportunity Institution authorized to provide research, educational information and other services

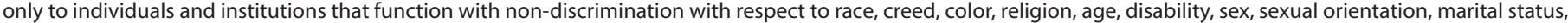

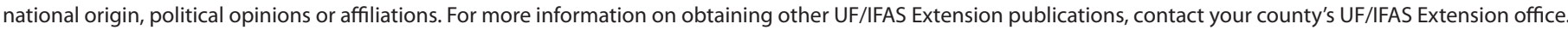
U.S. Department of Agriculture, UF/IFAS Extension Service, University of Florida, IFAS, Florida A \& M University Cooperative Extension Program, and Boards of County Commissioners Cooperating. Nick T. Place, dean for UF/IFAS Extension. 


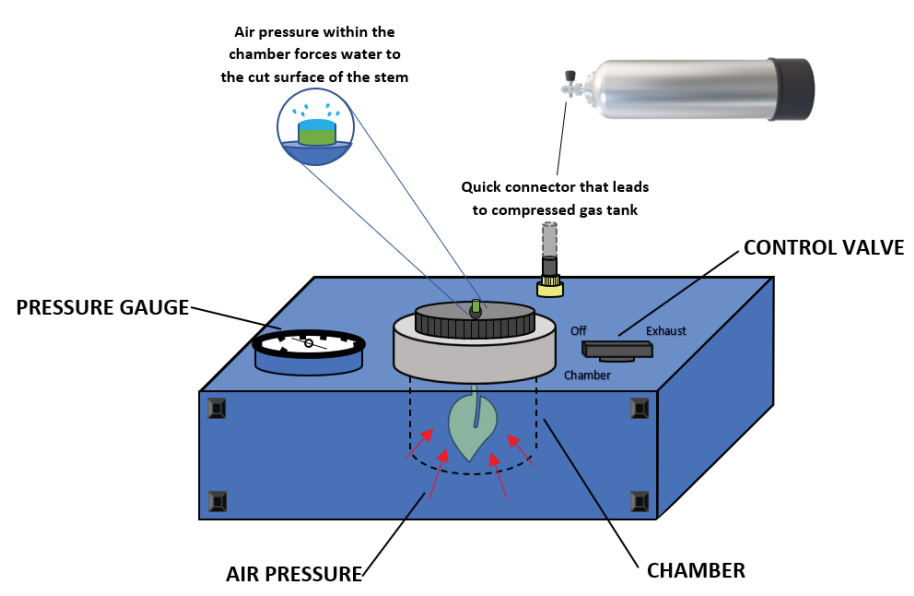

Figure 1. Schematic of a pressure "bomb."

Credits: Christian Bartell, UF/IFAS

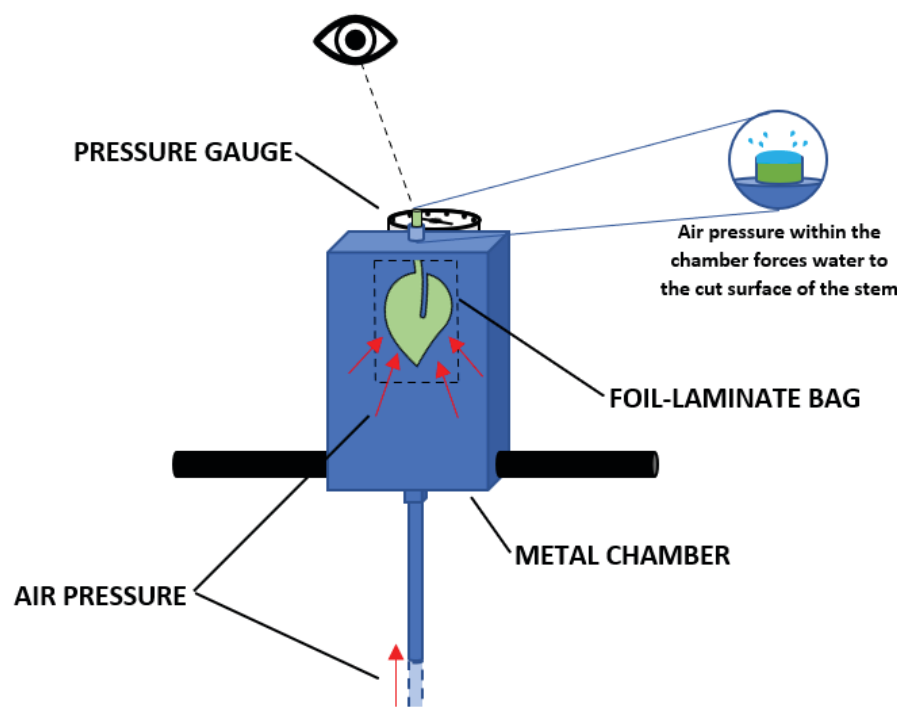

Figure 2. Schematic of a pump-up chamber. Credits: Christian Bartell, UF/IFAS

\section{Leaf Sample Preparation}

Leaf water potential measurements require preparing samples appropriately for good results. Leaf water potential can change throughout the day due to changes in weather conditions, so the time of sampling and measurement is critical. It is generally recommended to be taken around noon (called mid-day water potential measurements) because water potential measurements are high at mid-day (Williams and Araujo 2002). The steps involved in leaf sample preparation in the field are shown below.

1. Identify a representative, healthy leaf.

2. Cover the leaf being sampled using a reflective bag (Figure 3a). Keep the leaf covered with a reflective bag for about 20 minutes. This will slow the rate of transpiration in the plant, allowing for a more accurate determination of the plant's current water status.
3. After 20 minutes, remove the leaf (with the stem which is called the petiole) from the plant by cutting the petiole, using a sharp blade to provide a clean cut (Figure $3 b$ ). Leave as much of the petiole as possible and do not recut the petiole after the initial cut. Once the petiole is cut, the tension of the water column is disrupted, and the tension causes the water within the plant to recede into the sample, similarly to a rubber band under tension being cut.

4. Measure leaf water potential. Below are the procedures for measuring leaf water potential.

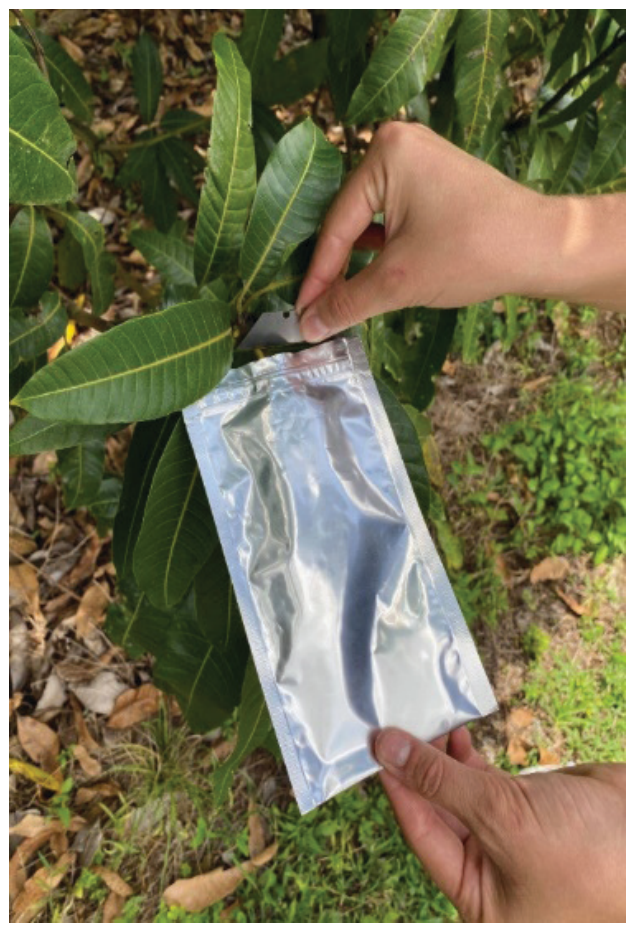

Figure 3. Covering a leaf sample with a reflective bag and cutting a leaf sample for measurement.

Credits: Christian Bartell, UF/IFAS

\section{Pump-Up Chamber}

With a pump-up chamber, samples can be measured quickly by immediately transferring the newly cut sample to the chamber. Unlike the pressure "bomb," the pump-up chamber is an all-in-one apparatus that requires manual pressurization. This device is lightweight and has no pressurized gas tank, making it portable and easy to use in prolonged field settings.

1. With the reflective bag still in place, place the sample with the cut surface protruding through the lid of the chamber and tighten the lid to create an airtight seal. Be sure to tighten the lid sufficiently so that no air will leak from around the sides of the petiole during pumping. 
2. Lock the lid in place using the two metal pins. This holds the lid in place while the chamber is being pressurized.

3. Once the sample and lid have been secured properly, start applying pressure slowly by performing a full end-to-end pump of the chamber. Following each pump, observe whether water is coming out of the protruding cut end of the petiole. Continue this process until the water is observed at the cut surface.

4. Once water is observed, pressure is no longer applied, and the chamber pressure is recorded. When tension is observed, a negative value is typically recorded, as the value represents water stress as a "deficit."
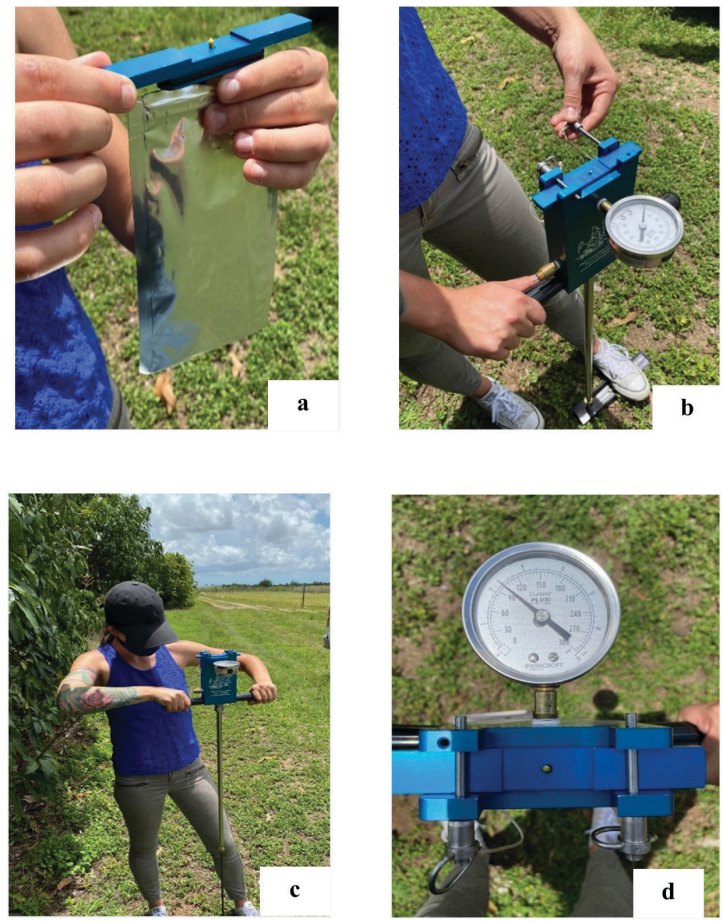

Figure 4. Steps $(a-d)$ for measuring leaf water potential using the pump-up chamber method.

Credits: Christian Bartell, UF/IFAS

\section{Pressure "Bomb"}

This technique requires an external pressure source. Often samples are transported to the lab. Samples need to be put in a cooler with ice during transport to the lab to prevent evaporation from the leaf during transport. Below are the steps for measuring leaf water potential using a pressure "bomb" in the lab.

1. Connect the tubing from the compressed air tank to the pressure chamber and open the flow of gas to the pressure "bomb."

2. Remove the chamber lid from the pressure "bomb."

Like the pump-up chamber, samples are measured individually by inserting the petiole through the bottom of the lid, exposing the cut end of the petiole, and then securing the petiole in the light by rotating the top of the lid clockwise until the petiole is firmly sealed in the lid. This lid will be under pressure, so it is important that no air escapes from around the petiole after the chamber is pressurized.

3. Put the lid on the chamber with the leaf blade inside the chamber and cut the end of the petiole visible on the outside. Tightly secure the lid on the chamber by turning it clockwise until it "locks" into the pressure chamber.

4. Once the sample is locked in place, rotate the chamber valve from the "off" position to the "chamber" position to begin pressurizing the chamber. Examine the protruding end of the petiole until liquid is observed and return the chamber valve immediately to the "off" position.

5. With the switch positioned "off," the gauge will indicate the pressure at which water was observed, which corresponds to the leaf water potential. To work with another leaf sample, first, turn the chamber valve to the "exhaust" position to depressurize the system and remove the chamber lid and the sample.
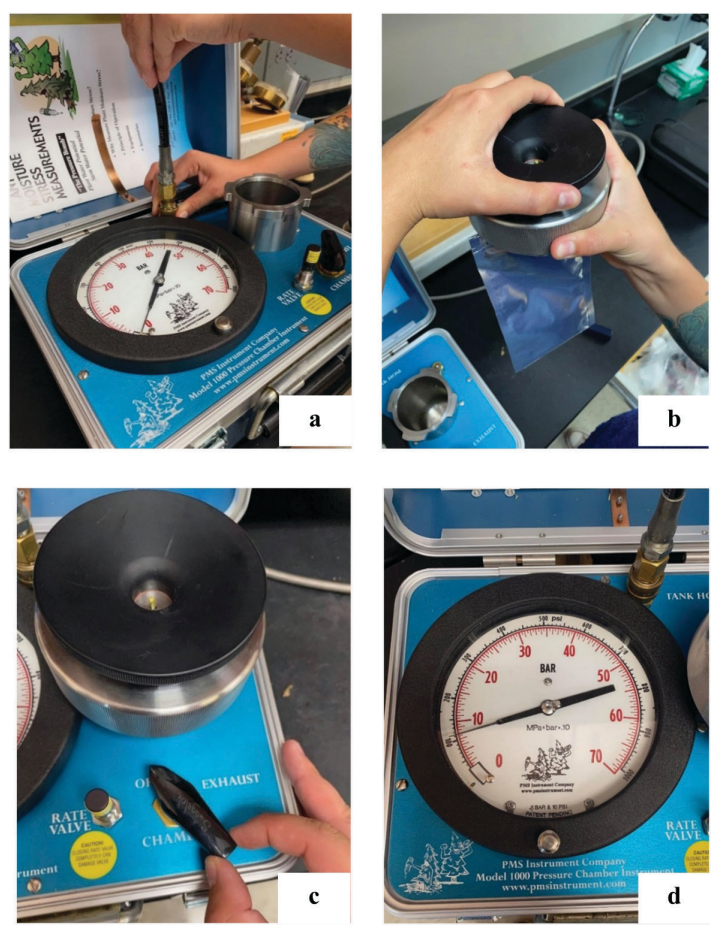

Figure 5. Steps $(a-d)$ for measuring leaf water potential using the pressure "bomb" method.

Credits: Christian Bartell, UF/IFAS 


\section{Advantages and Disadvantages of the Two Methods}

Both the pump-up chamber and the pressure "bomb" are useful tools for measuring leaf water potential. However, each method has advantages and disadvantages. The advantages and disadvantages of each method are summarized below.

\begin{tabular}{|c|c|}
\hline Pump-Up Chamber & Pressure "Bomb" \\
\hline Advantages: & Advantages: \\
\hline $\begin{array}{l}\text { Cheap compared to pressure } \\
\text { "bomb" }\end{array}$ & $\begin{array}{l}\text { Standard method for measuring } \\
\text { leaf water potential }\end{array}$ \\
\hline Light and portable & $\begin{array}{l}\text { Could be portable using a small, } \\
\text { pressurized gas tank }\end{array}$ \\
\hline $\begin{array}{l}\text { No need for external pressurized } \\
\text { gas }\end{array}$ & $\begin{array}{l}\text { Fixed setup makes it easy to } \\
\text { observe the sample }\end{array}$ \\
\hline \multicolumn{2}{|l|}{$\begin{array}{l}\text { Easy for on-the-spot } \\
\text { measurement }\end{array}$} \\
\hline \multicolumn{2}{|l|}{ Easy and quick to set up } \\
\hline Disadvantages: & Disadvantages: \\
\hline $\begin{array}{l}\text { Pumping can get tiring over } \\
\text { long periods of time }\end{array}$ & Heavy to carry around \\
\hline Not as durable & Requires a pressurized gas tank \\
\hline $\begin{array}{l}\text { Could be difficult to observe; can } \\
\text { only observe between pumps }\end{array}$ & $\begin{array}{l}\text { Relatively expensive compared } \\
\text { to pump-up chamber }\end{array}$ \\
\hline
\end{tabular}

\section{Comparison of Pressure "Bomb" vs. Pump-Up Chamber}

Leaf water potential measurements from the pressure "bomb" versus pump-up chamber methods were compared for sweet corn and green beans (Figure 6). Measurements were taken from well-developed sweet corn and green bean plants. Leaf water potential measurements were measured on paired leaves from the same plant. Leaf sampling was done around noon following the steps discussed above. Two leaves were sampled for measurements using the two methods. Water potential measure with the pressure "bomb" and pump-up chamber showed a good agreement for sweet corn compared to green beans. However, the pump-up chamber method tended to underestimate leaf water potential for both crops.

\section{Summary}

Leaf water potential could be a good indicator of crop water stress and provide useful information for irrigation scheduling. This article shows the steps for measuring leaf water potential using pressure "bomb" and pump-up chamber methods. Results from the two methods showed a better agreement for sweet corn than green beans. This suggests that crop type should be taken into consideration when choosing a leaf water potential measurement method. The pressure chamber method is the standard method, and results are not always the same between methods. Therefore, when using the pump method, we suggest first correlating it to the pressure "bomb" method to be sure that the two methods are in good agreement.
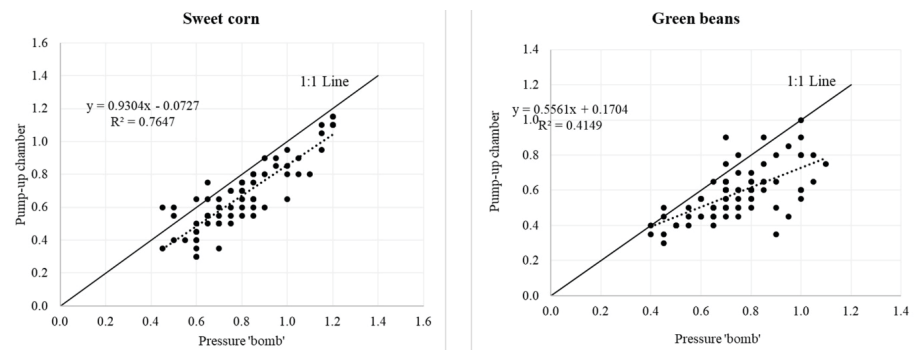

Figure 6. Comparison of leaf water potential measurements (Megapascal; Mpa) using the pressure "bomb" and pump-up chamber methods.

Credits: Haimanote Bayabil, UF/IFAS

\section{Acknowledgments}

This factsheet was developed based on a research project funded by the National Institute of Food and Agriculture, U.S. Department of Agriculture, under award number 2020-67021-31965. Any opinions, findings, conclusions, or recommendations expressed in this publication are those of the authors and do not necessarily reflect the view of the U.S. Department of Agriculture.

\section{References}

Cochard, H., S. Forestier, and T. Améglio. 2001. "A New Validation of the Scholander Pressure Chamber Technique Based on Stem Diameter Variations." Journal of Experimental Botany 52(359): 1361-1365. https://doi.org/10.1093/ jexbot/52.359.1361

Fulton, A., R. Buchner, C. Gilles, B. Olson, N. Bertagna, J. Walton, L. Schwankl, and K. Shackel. 2001. "Rapid Equilibration of Leaf and Stem Water Potential under Field Conditions in Almonds, Walnuts, and Prunes." HortTechnology Horttech 11(4): 609-615. https://doi.org/10.21273/ HORTTECH.11.4.609

Scholander, P. F., E. D. Bradstreet, E. A. Hemmingsen, and H. T. Hammel. 1965. "Sap Pressure in Vascular Plants." Science 148(3668): 339 LP-346. https://doi.org/10.1126/ science.148.3668.339

Waring, R. H., and B. D. Cleary. 1967. "Plant Moisture Stress: Evaluation by Pressure Bomb.” Science 155(3767). http://www.jstor.org/stable/1720146 